\section{Applications of Physics in Industry: the example of IABG, Ottobrunn}

(IABG) Industrieanlagen-Betriebsgesellschaft mbH, Einsteinstraße 20, D-85521 Ottobrunn, Germany

\section{Introduction}

Physics, perhaps more than other fields of research, is the underlying science for applications in many areas of industrial importance: for example semiconductors, chemicals and environmental sectors, to name just a few. Yet, although physics provides the scientific basis for a wide range of industries, it does not enjoy the same visibility as other subjects, such as chemistry or biotechnology. During his academic training and formative years, a physicist does not usually consider it a natural consequence to apply his discipline to industry. Uppermost in his mind is research applied only to the advancement of his subject. But the picture is changing now, quite rapidly.

For instance, in the publicly-funded, more expensive research areas, governmental pressure and public awareness are greater to ensure that the work helps improve the quality of life, and create wealth at the same time. And industries offer interestingly diverse workplaces for physicists to invest their talents in achieving these aims, by generating new products and control instrumentation essential to our everyday lives. University physics departments too, are increasingly rising to the cultural change and challenge of directing research efforts where the results may benefit industrial users or humankind in general.

How do 'academic' physicists perceive the work of their industrially applied colleagues? And how is contact promoted between the two facets of the same discipline - between the theoretical and the practical? To look for some answers (and to ask even more questions) an invitation of a day trip into the inner complex of a company like IABG, near Munich, was readily accepted.

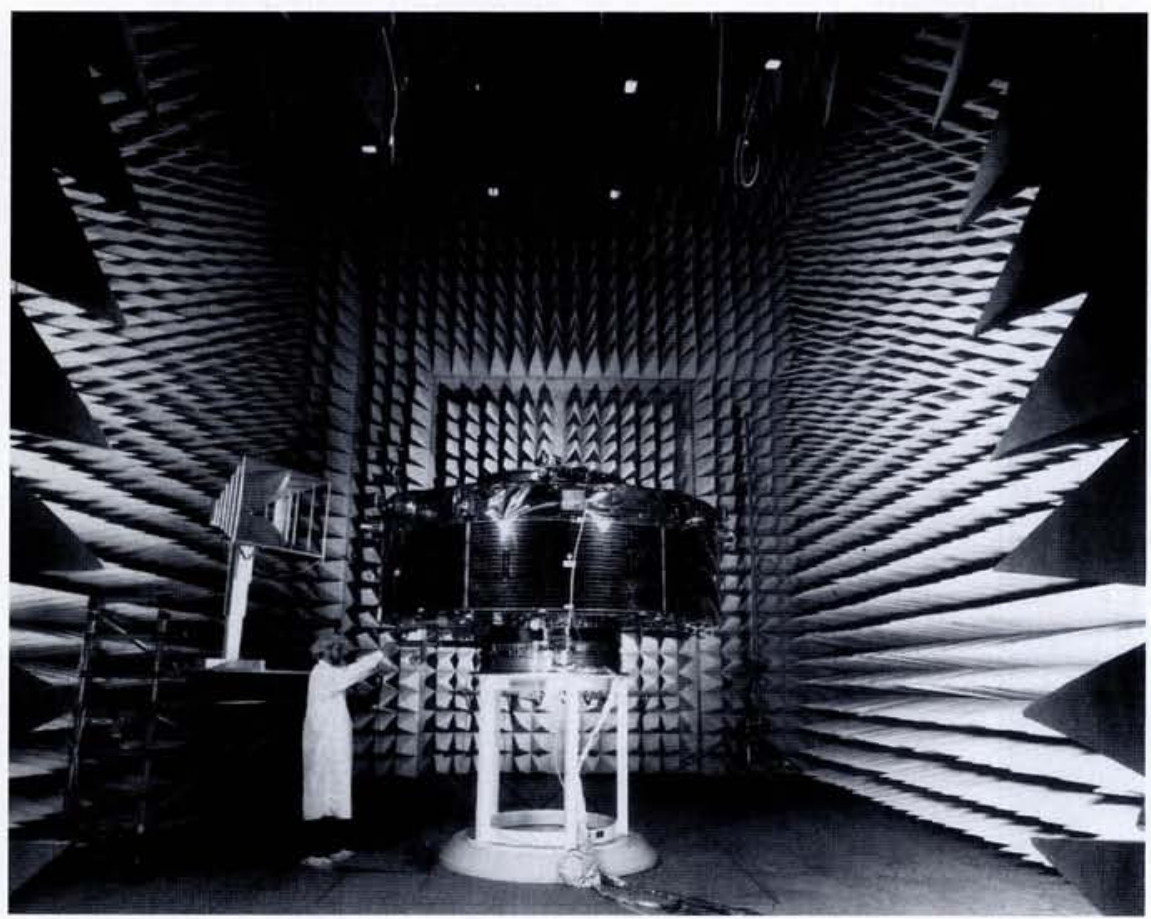

Fig. 1. Electromagnetic compatibility system level test on the CLUSTER spacecraft

\section{Corporate Profile}

IABG is the company that defines "A New Dimension in Technical Service". Technical Services is the application, in an interdisciplinary and flexible approach, of modern technology by highly educated and trained scientists, engineers and analysts to deliver timely and costeffective solutions to specific client problems. To succeed in a changing world and the dynamic industries that go with it, effort, sacrifice and determination, as well as talent, skill and leadership are the essential ingredients. Some 1400 employees are focused on serving clients' needs and expanding into challenging new business areas covering a wide range of technologies.

Often the challenge is to merge information technology with other technical disciplines to achieve optimum solutions. Here is where a physicist's training can be most effective. About two thirds of IABG's employees have academic degrees; the statistics are: $13 \%$ physicists; $17 \%$ computer scientists/mathematicians; $5 \%$ environmental technologists/chemists; $5 \%$ aeronautical engineers; $29 \%$ mechanical engineers; $5 \%$ transportation/ construction and other disciplines; $8 \%$ management scientists/economists; $18 \%$ communication/electrical engineers.

Physicists weigh in at fourth place in this breakdown of disciplines, which may be a reflection of both the character of current projects, as well as the fact that physicists do not often apply for work in any of the other disciplines, something they could surely do. Companies as large as IABG can afford to train employees on the job, and physicists "by training, ought to be able to do any job put before them" (quotation by a famous Cavendish professor).

$I A B G$ 's general business areas may be grouped under the separate headings: Information Technology; Defence; Aerospace; Environmental Protection; Manufacturing and Logistics; Transportation. To solve its customers' technical and operational problems, the following services are offered:

- Strategic planning and consulting

- Operational and technical analyses

- Research and development

- Simulation and optimization

- Test and evaluation

- Systems development and integration. And the basic principles behind its mission statement are proclaimed to be: quality, integrity, competitiveness and cooperation. That these words are not 

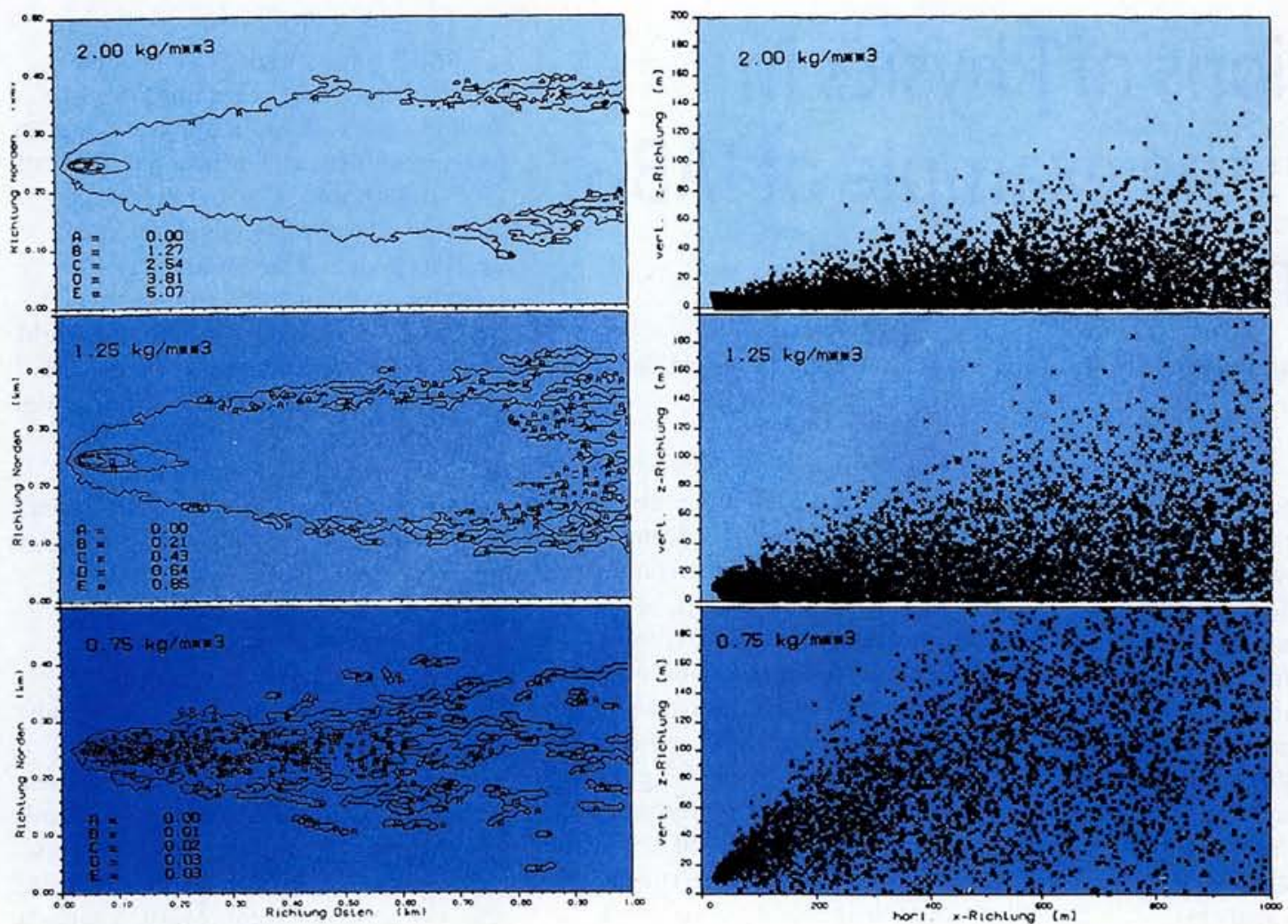

Fig. 2. The effect of varying density of emitted gases on contamination dispersion close to the source: horizontal distribution of gas concentration at ground level (left), vertical distribution of the cloud of gas (right). Calculated using AIRPOL

mere advertising slogans is impressively demonstrated by the customer lists and missions, past and present, and the gross annual turnover of some $300 \mathrm{MDM}$. Amongst our readers, both the prospective clients and future physicists in industry may be interested in a short synopsis of the topics under each business area heading, and that will round-off the company's profile - as well as make clear the difficult choice a visitor faces on a day tour:

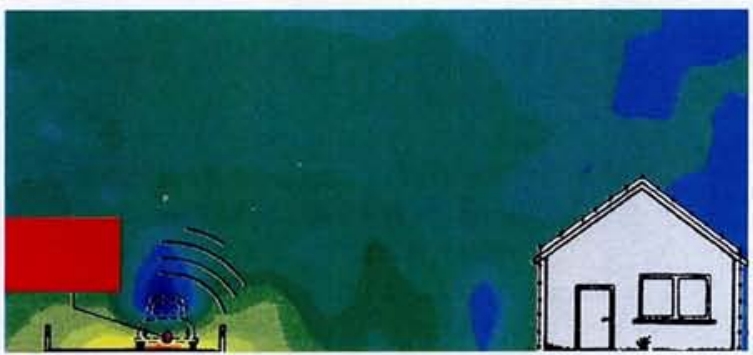

Information Technology

- Systems development/integration

- Command and control systems

- Telecommunications

- Logistics information systems

- Administrative and office systems

- Software technology

- Business process re-engineering

\section{Defence}

- Technical analysis, evaluation and simulation of:

- Operational profiles
Fig. 3. Noise propagation with/without abatement protection
- System performance

- Weapon effectiveness

- Technical feasibility

- Protection and camouflage

- Systems compatibility

- Technical risk

- Implementation support for:

- Land-based combat systems

- Aircraft and helicopters

- Air defence and missile systems

- Naval systems.

Aerospace; European Space Test Centre

- Space simulation

- Thermal vacuum test

- Acoustics and acoustic strength

- Vibration and shock

- Modal analysis and mass attributes

- Electromagnetic compatibility

- Magnetic field simulation

- Technical analyses of space systems

Environmental Protection

- Screening for environmental damage

- Risk assessment

- Environmental damage remediation

- Air-based sensorics and photogrammetry

- Mobile analysis

- Environmental information systems

- Environmental simulation technology

- Regional development planning

Manufacturing and Logistics

- Warehouse logistics

- Production planning 


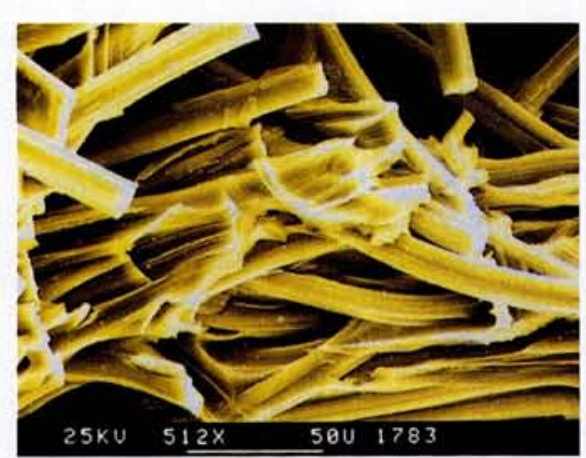

Fig. 4. Microstructure of C/SiC material

- Production control and automation

- Transport and distribution logistics

- Automation and test systems

- Inspection and maintenance management

- Schedule planning

Transportation

- Transport planning:

- Integrated transport concepts

- Regional transport concepts

- Site analyses

- Environmental impact analyses

- System management studies (road, rail, air)
- Vehicle technology:

- Vehicle/propulsion technology

- Test facilities

- Safety/reliability

- Environment

(acoustics, emissions, climate, corrosion)

- Simulation technology

- Operation of large-scale facilities

- Telematics

- Transrapid test site

It is evident that IABG is a very large, efficient and versatile organisation.

The success of all the divisions of IABG can surely in no little measure be attributed to the application of physics in any of its many forms. There is testing, using highly accurate metrology to evaluate material properties of new products and for quality control; computer modelling: simulation for research and development; the design of new materials for specific purposes, tailored to solve customers' problems as creatively, ingeniously and elegantly, as well as costeffectively as possible.

How not to be overwhelmed by the sheer size of such an organisation? Which
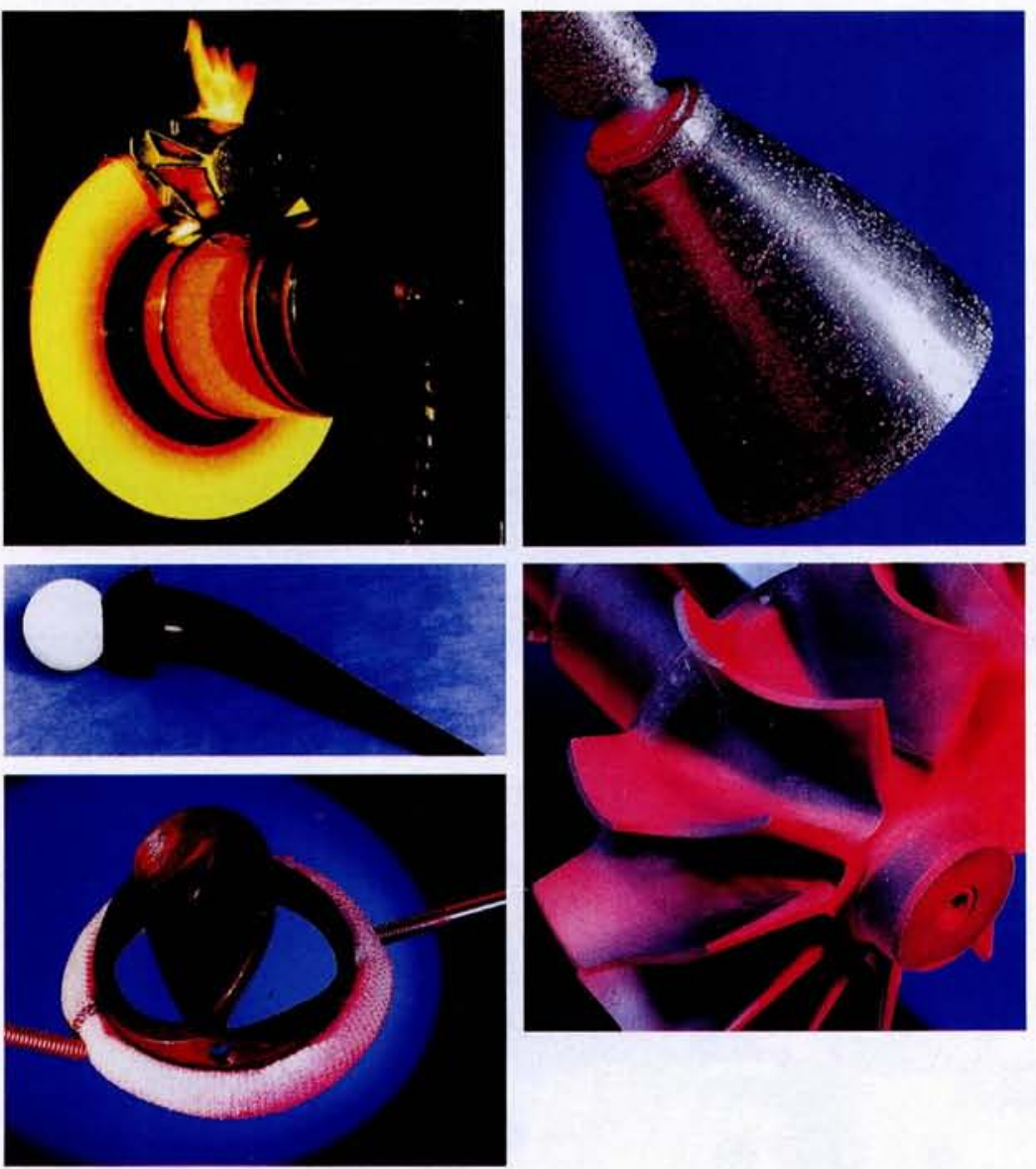

Fig. 5. C/SiC braking disc under stress (top left); C/SiC satellite propulsion nozzle (top right); an extremely light and bio-compatible C/SiC prototype hip joint prosthesis (middle); heart valve prototype with improved flow profile (bottom left); light and heat resistant: C/SiC turbine blades (bottom right)

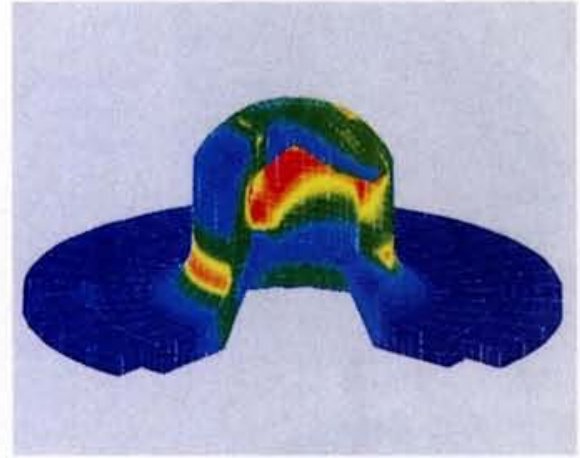

Fig. 6. Strength calculations on ARIANE 5 components: stress and deformation analysis of a cardan joint. Distribution of the equivalent stress on the ball shaft. (By courtesy of MAN Technology)

laboratories should be chosen for a first glimpse behind the scenes? Eventually, it was decided to make a start by visiting some of the testing bays in the following sectors: environmental protection, transport systems, and some aspects of space research (new materials, Fig. 4 and 5). A discussion at the end of the day about the employment prospects of physicists in the firm finally rounded everything off.

\section{Environmental Protection}

Industrialisation has given us a high standard of living. The price we pay for it is the destruction of our environment. Pollution of the air, soil and water, plus the spectre of a climate breakdown, are frightening everyday companions. We are every one of us responsible and called upon to avoid and remediate these hazards to Life and the damage to our planet Earth.

An example: one of the more serious problems Germany faces in the former eastern zone is the soil and water contamination by toxic chemicals irresponsibly deposited by the former government. More worrying still is the possibility of radiological leakages from corroding containers, not to mention rusting weaponry, dumped by the former Soviet military. A major IABG project was the management for stabilization and remediation of these problems, including a final assessment of residual risks. The work encompassed the screening, initial evaluation and risk assessment of suspected contaminated sites and properties (some 1000; a total of 250,000 hectares) formerly used by the Soviet troops in East Germany.

Data acquisition is undertaken from the air too: aerial photos can be superimposed on an evaluation of thermal or magnetic anomalies. Problem sites can 


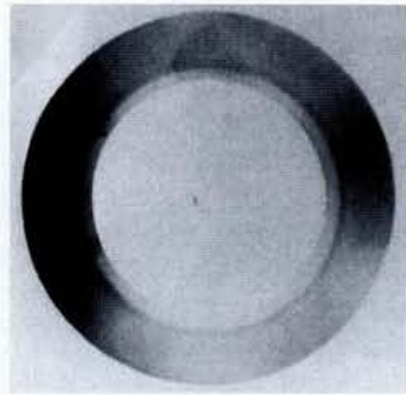

Fig. 7.

Density

variations in ceramic

rings.

Above:

the neutron radiograph; below:

the $x$-ray

investigation

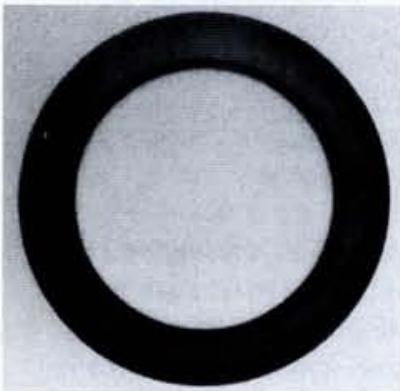

also be detected by on-the-spot analyses performed by an IABG mobile sampling and testing unit. Highly accurate chemical analysis devices screen the samples for mineral oils, halogenated hydrocarbons, explosives and metabolites. Remediation engineering oversees the recovery and disposal of the hazardous soil and subsoil; the project is monitored down to the necessary backfilling.

Another important problem that cannot be ignored in ecological planning and policy is air pollution and the influence on climate undoubtedly caused by the emission of toxic fumes and reactive trace gases by such sources as industry, traffic and households. Accurate instrumentation must be deployed to make fast, inexpensive and thorough assessments of contamination dispersion. This latter begins with atmospheric transport, chemical transformation and finally deposition on the ground and in water. Numerical simulation using mathematical-physical models is ideal for dealing with the problem: AIRPOL is a simulation model for contamination dispersion (see Fig. 2) and deposition of inert and reactive trace gases in the atmosphere.

The parameters that are accounted for by the AIRPOL programme are: site and ground properties; critical meteorological dispersion conditions (wind, temperature, humidity, solar irradiation); emission distribution; reaction kinetics, transport, diffusion, and deposition of contaminants; release of heavy gases; effect of trace gases, aerosols and radiative heat on the local climate. Coupled with the dispersion model is a climate model that permits the assessment of pollution by photo-chemical smog and ozone gas.

Another area of environmental simulation is in noise pollution (see Fig. 3). Noise levels (noise maps) are recorded in urban areas and the effect of noise protection measures tested. The results are fed back into noise optimisation for buildings or alternative building proposals where necessary.

\section{Transport Systems: Testing and Analysis}

Here the emphasis is on all aspects of material fatigue which defines the risk to which transport vehicles of road, rail or air are subject, permitting realistic estimates of their service life. For instance, in avionics we all demand the highest standards for materials and overall system reliability, most of us as lay-travellers not really appreciating the extreme ambient environment to which the equipment is exposed at normal flight altitudes (e.g. radiation damage, low temperatures). Assurance of quality and reliability are key requirements in the harsh competitive market of today's technical devices. An exhaustive list of all the testing equipment which IABG offers its clients cannot be given here; those mentioned are the ones which impressed this visitor most.

Just some of the testing options IABG has at its disposal are: climate simulation with accelerated weathering in the laboratory; corrosive atmospheres; environmental aging; reliability and fatigue life tests (fatigue strength and fracture mechanics); solar simulation test chamber. There are several large drive-in climate and weathering chambers (with temperatures ranging from $-80^{\circ} \mathrm{C}$ to $+150^{\circ} \mathrm{C}$ ). Environmental, cold start and exhaust tests are carried out on vehicles and vehicle components. For this purpose they can be subjected to extreme cold, dry heat, humidity, reduced pressure (altitude tests) and dust (sand) or snow-laden intake air.

In addition there are services for high-temperature testing (thermomechanics, thermo-chemistry), as well as shock testing (impact loading under extreme driving conditions; strength tests on vehicle axles) and vibration simulation studies (e.g. multi-axis vibration of space probes; earthquake simulation for power plant equipment).
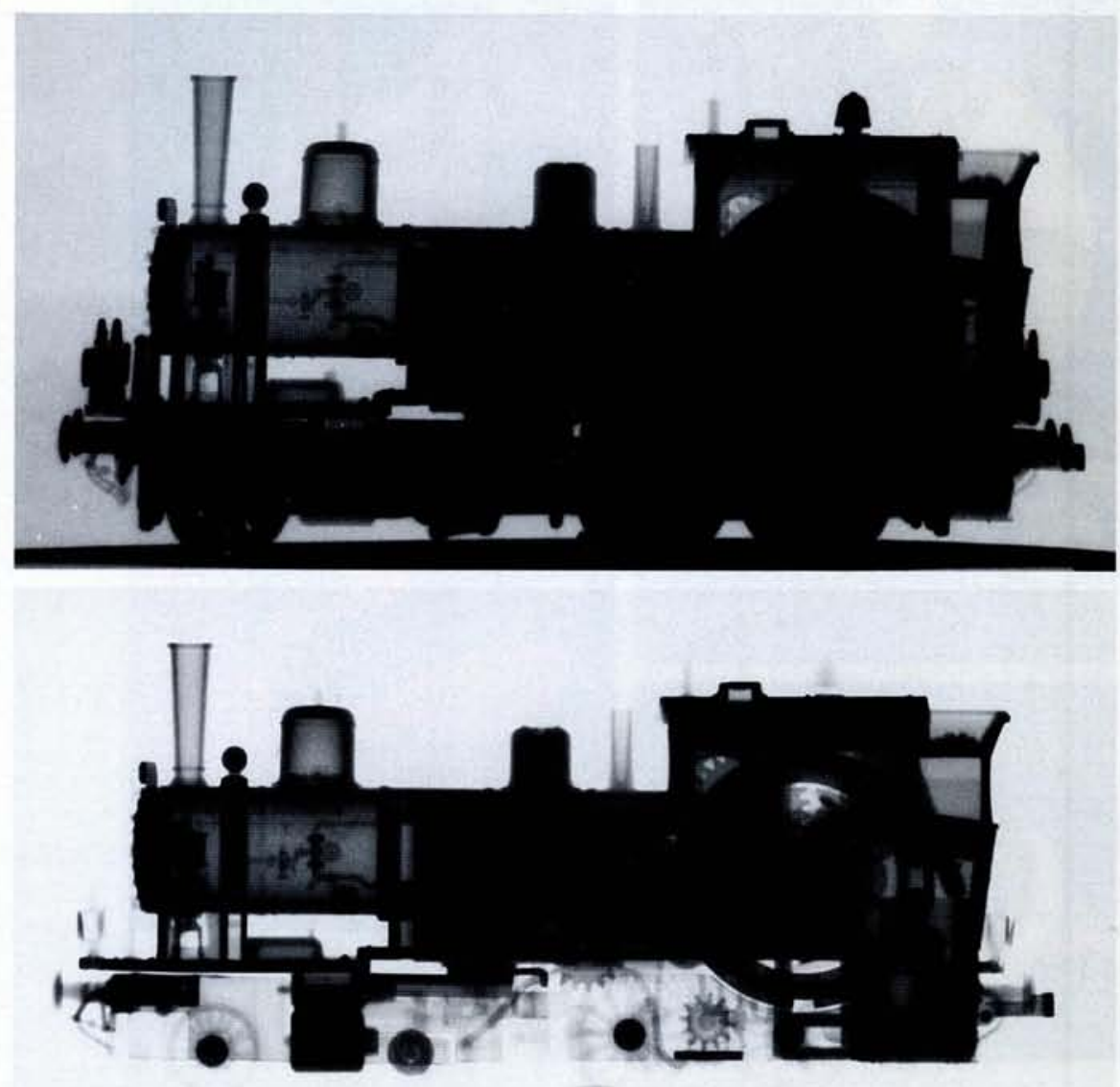

Fig. 8. Neutron radiograph (above) and $x$-ray (below) of a model railway engine 
To follow up, training concepts and systems are developed for operations and maintenance personnel in public transportation. Crash processes are simulated using models for extreme dynamic sequences; resultant information is used in structure improvement with regard to collision and passenger safety, and in the assessment of energy absorption systems (e.g. air-bags).

Rail vehicle technology encompasses a full spectrum of investigations. Innovative materials, their design and production for lightweight structures are studied, the emphasis being on collision safety. Acoustic and structure vibrations are measured and calculated, running gears are optimized, to reduce vibration in vehicles. Very important ecological work is being done in the energy conservation sector: propulsion technology and the alternatives; consumption, emissions, and energy recovery are further topics.

In fact, it is in the diversity of these testing bays that the visitor fully appreciates the consequences of multidisciplinary teamwork. The testing and analysis centre at IABG disposes of the most modern facilities and devices; experts in many different fields piece together analytical puzzles to produce full profiles of a test object. The results of these services most surely give great satisfaction and thereby motivation to the engineers, scientists and technicians involved. Lastly, how much happier is a consumer who knows his chosen product has been literally turned inside out, every part of it meticulously checked, to ensure he has the best that money can buy!

\section{New Materials and Testing}

$\mathrm{C} / \mathrm{SiC}, \mathrm{SiC} / \mathrm{SiC}$ : fibre reinforced ceramic composites - these are new materials developed by the aerospace industries, in which IABG was actively involved. This is really astonishing stuff: its surface has a grey metallic sheen, glinting when it catches the light rather like granite - but light as a feather to hold. It is another promising development in the list of space-age spin-offs which have so far given us teflon, ceramic or glass-fibre reinforced plastics, to name just three.

The extreme working conditions in space travel call for materials of low density, high temperature resilience, high strength and rigidity even at high temperatures, maximum wear and tear, corrosion and thermo-shock resistance, and damage-inhibiting fracture behaviour. Figure 5 shows some of the fields of application of this novel material. Besides furnishing ultra-light yet rigid construction elements for the space and medical industries, it is used for mirrors in astronomy and opto-electronics. But there are a host of further applications to be exploited in numerous other fields too.

This is a new class of composite, uniting the properties of two well-known materials: the extremely high temperature, chemical and abrasive resistance of ceramics, with the astounding strength and rigidity of carbon fibres.

Its material properties are of course determined in all the tests of which IABG is so capable; fabricated components too are subjected to mechanical and thermal tests. Strength analysis is also performed in simulation (Fig.6).

In fact, materials testing in general is essential to damage analysis and is also an integral element of quality assurance, a prime objective of all industries. For the evaluation of material properties of metals, ceramics and plastics as well as composites, metallography, fractography, corrosion and mechanical tests can be performed on site.

Non-destructive testing of metal, ceramic and plastic materials is performed in a neutron radiography apparatus which is used to detect corrosion, adhesive effects and moisture (Figs. 7 and 8). IABG is also equipped for all the other standard methods of non-destructive testing, using $\mathrm{x}$-rays, ultrasonics, eddy currents, acoustic emission, neutron activation and dye penetration.

The by now slightly footsore, amazed as well as dazed visitor, decided to end the tour there, and limped from the scene bearing numerous rather weighty but enlightening brochures home as trophies.

\section{Discussion}

In industry, as distinct from university research, the work on a project is calculated and charged by the hour. This necessitates an exact definition of the working programme: there can be no experiments off at a tangent, where physical instinct may preciptate an entirely new set of interesting and promising problems which may or may not produce valuable spin-offs with the answers. Rather, in industry, it is "feet on the ground" direct problem solving, as practicably and economically as possible. So this pin-points one of the difficulties physicists may have in adjusting to an industrial way of life: the difference in working modes. This is one of the main reasons for industry's reluctance to take a universtity physicist onto their staff after the age of 30 (some IABG directors mellow that to a young 35): "their life in the ivory towers have spoilt them". Well, maybe some industrialists have been away from university for quite a long time - said ivory towers are a fiction nowadays. And university budgets are often wishful thinking...

Yet it might still be argued that, when there are cooperative programmes between university and industry, the industrial partner (strictly bound within a time/cost frame) is not in such a favourable position as the university institute (comparatively more working freedom). In the 5 th. R \& D Framework Programme (see News from Brussels, this issue), currently being elaborated by the European Commission, this is an important point which should not be neglected when designing the collaboration projects (i.e. SMEs and universities).

A physicist in industry today might be regarded as a bridge between his scientific base and industrial management: his problem-solving training as a scientist can stand him in good stead here. Added to this, his clear recognition of the problem and precise articulation of feasible solutions can help managerial decisionmaking. Sometimes, in analytical work for example, there can be no comparison with an appropriate experiment. In simulation programmes (e.g. for industrial management) experiments are not possible.

Finally, in these difficult economic times of declining or stagnant public budgets and slow private investment, depending as we all do on politicians' mores in one way or another, those shapers of our past, present and future ought somehow to be trained in the use of options. So, for decision-making at the government level (and IABG, on the strength of its expertise and by default, has an influential hand in many departments), the dynamics of a system need to be fully researched (such as the environmental or humanitarian interactions).

Software people usually think statically and the handcraft of physics can be very useful in the field of analyses of models in dynamic systems. Again, it must be emphasized that, for success in industrial endeavours, the physicist must never be too theoretical: may one eye be closed and dreaming, the other must always be alert and focused on practical exploitation. 